\title{
CORRESPONDENCE
}

\section{Neurological conditions presenting as airway reflux cough}

\section{To the Editor:}

The association of cough with neurological conditions is well described [1-4]. Herein, we report four patients with chronic cough who each presented to our cough clinic (Castle Hill Hospital, Cottingham, UK) with a different neurological diagnosis. Each of the patients had normal chest radiology and pulmonary function, they were not on angiotension converting enzyme inhibitors, and no obvious underlying respiratory pathology was identified. A summary of all the relevant investigations performed on each patient are detailed in table 1 .

\section{CASE 1: MONONEURITIS MULTIPLEX}

A 66-yr-old nonsmoking male presented with a non-productive cough for several years which was profound on rising from bed in the morning and associated with eating, but no symptoms of dyspepsia. Interestingly, he also complained of numbness over the left side of his head up to his mid upper arm. Clinical examination showed wasting of scapular muscles and biceps with absent sensations and areflexia in both lower limbs.

Oesophageal $\mathrm{pH}$ monitoring and manometry were abnormal, with a DeMeester score of 18.3. Blood tests and cerebrospinal fluid analysis were normal. Anatomical and malignant pathology was excluded by radiological investigations. Neurophysiological studies revealed sensory polyneuropathy with a dorsal column lesion and focal radiculopathy at the right cervical (C)3, C4 and, possibly C6, levels. Autonomic testing of heart rate variability showed lack of variation of heart rate during inspiration and expiration (table 1).

A diagnosis of mononeuritis multiplex was made and cough was probably secondary to vagal neuropathy causing airways reflux as a part of this syndrome. His cough was refractory to various pharmacological interventions.

\section{CASE 2: HOLMES-ADIE SYNDROME}

A 55-yr-old nonsmoking female presented with a 20-yr history of dry cough. Previous fibreoptic endoscopy had shown a small hiatus hernia and mild oesophagitis. In addition to dyspepsia she presented with a classic history of airway reflux cough. She scored 45 out of 70 on the Hull Airways Reflux Questionnaire (HARQ) [5]. Her cough was worse when she lay down and was typically triggered by eating certain foods. Dyspepsia continued despite administration of proton-pump inhibitors (PPIs). On examination her left pupil was enlarged and areflexic, with near light dissociation (fig. 1). Heart rate variability testing was abnormal (table 1$)$.

The patient's cough was resistant to numerous trials of treatment with PPIs, pro-motility agents, baclofen, and nasal and oral steroids. Holmes-Adie syndrome has been reported in patients with chronic cough [1, 2]. Autonomic dysfunction is a common feature of this condition and has been attributed to lesions in both afferent and efferent sympathetic and parasympathetic neurons. Airways reflux secondary to vagal dysfunction is a possible aetiology of cough in this patient.

\section{CASE 3: DIABETIC AUTONOMIC NEUROPATHY}

A 58-yr-old ex-smoker with a 100 pack-yr smoking history presented with a 2-yr history of nonproductive cough triggered by eating, and associated with hoarseness of voice and a constant urge to clear his throat. He also complained of excessive sweating at night requiring a couple of changes of clothes. He had a 10-yr history of type- 2 diabetes mellitus with peripheral neuropathy and background retinopathy, as well as a positive family history of type-2 diabetes mellitus.

On examination he had a body mass index of $38.2 \mathrm{~kg} \cdot \mathrm{m}^{-2}$ and lower limb examination was consistent with stocking distribution of peripheral neuropathy. His HARQ score was 36 out of 70 suggesting airway reflux cough. Neurophysiological studies showed no evidence of large fibre motor and sensory neuropathy; however, small fibre polyneuropathy could not be excluded. Heart rate variability testing was abnormal (table 1).

A diagnosis of diabetic autonomic neuropathy with airway reflux cough was made. There is a reported higher prevalence of abnormal gastro-oesophageal reflux (GOR) among the asymptomatic diabetic population [6], with the existence of cardiovascular autonomic neuropathy, and there is a significant correlation between abnormal acid reflux and diabetic motor neuropathy [7]. Diabetic autonomic neuropathy presenting with an isolated cough possibly secondary to airways reflux has not been reported previously.

\section{CASE 4: HEREDITARY SENSORY NEUROPATHY 1}

A 51-yr-old nonsmoking railway inspector presented with a 30yr history of chronic cough which was brought on by certain foods and drinks, originally considered as asthma. Despite inhaled therapy he complained of unabated intermittent hoarseness of voice and a constant urge to clear his throat, features consistent with airway reflux cough. Of note, he had been suffering with walking difficulties for many years, with a strong family history of similar complaints.

On examination he was unable to heel-toe walk, joint position sense was abnormal at the great toes, vibration sense was lost below the ribs, he had pin prick loss below the mid-thigh and Romberg's test was positive. Nerve conduction studies revealed a pure sensory axonal neuropathy consistent with suspected hereditary sensory neuropathy 1 (HSN1), confirmed by specialist opinion. Blood analysis, methacholine challenge and citric acid cough challenge were within normal limits (table 1). 
TABLE 1 Summary of results of the four cases

\begin{tabular}{|c|c|c|c|c|}
\hline Blood tests & $\begin{array}{c}\text { Normal FBC, BCP and } \\
\text { inflammatory markers } \\
\text { Positive ANA titre }>1: 640 \\
\text { Negative ANCA } \\
\text { Negative antineuronal antibodies } \\
\text { Negative acetylcholine receptor } \\
\text { antibodies } \\
\text { Negative voltage-gated calcium } \\
\text { channel antibodies }\end{array}$ & $\begin{array}{l}\text { Normal FBC, } \mathrm{BCP} \text { and } \\
\text { inflammatory markers }\end{array}$ & $\begin{array}{l}\text { Normal FBC, BCP and } \\
\text { inflammatory markers }\end{array}$ & $\begin{array}{l}\text { Normal FBC, BCP and } \\
\text { inflammatory markers } \\
\text { Normal blood glucose, vitamin E } \\
\text { and B12 } \\
\text { Normal antiGQ1B antibody levels }\end{array}$ \\
\hline Lung function & Normal & Normal & Normal & Normal \\
\hline Radiology & $\begin{array}{l}\text { Normal chest radiograph, cervical } \\
\text { spine MRI and body CT scan }\end{array}$ & $\begin{array}{c}\text { Normal chest radiograph } \\
\text { and HRCT }\end{array}$ & Normal chest radiograph & Normal chest radiograph \\
\hline HARQ score s $^{\#}$ & & $45 / 70$ & $36 / 70$ & \\
\hline $\begin{array}{l}\text { Autonomic test: } \\
\text { HRV }\end{array}$ & 9 beats $\cdot \mathrm{min}^{-1}$ & 4 beats $\cdot \mathrm{min}^{-1}$ & 9.75 beats $\cdot \min ^{-1}$ & \\
\hline
\end{tabular}

HARQ: Hull Airways Reflux Questionnaire; HRV: heart rate variability; FBC: full blood count; BCP: biochemical profile; ANA: anti-nuclear antibody; ANCA: anti-neutrophil cytoplasmic antibody; MRI: magnetic resonance imaging; CT: computed tomography; HRCT: high-resolution CT; CSF: cerebrospinal fluid; OGD: oesophago-

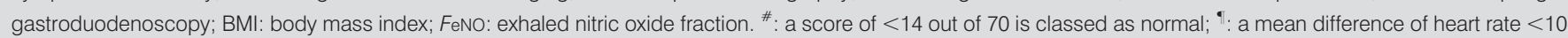
during inhaling and exhaling is classed as abnormal; + : a score $<14.7$ is classed as normal.

A diagnosis of HSN1 associated airway reflux cough was made. Although baclofen improved his cough, it was discontinued due to side-effects. Thus, his treatment was altered to PPIs and morphine sulfate as well as life style changes, such as avoidance of citrated drinks and caffeine, with a significant therapeutic effect.

HSN1 is a group of dominantly inherited degenerative disorders of the peripheral nerve in which sensory features are more prominent than motor features. A new form of HSN1

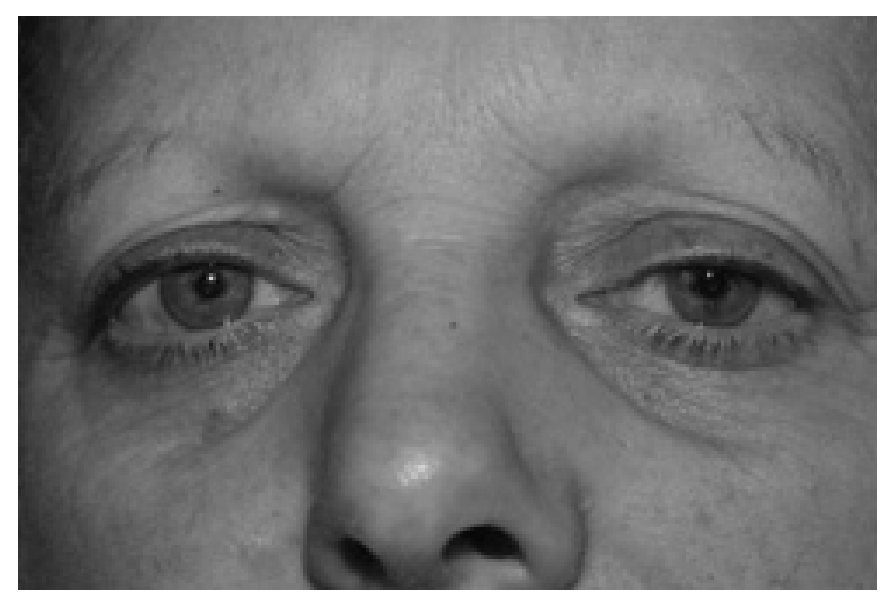

FIGURE 1. Dilated tonic left pupil in case 2 with Holmes-Adie syndrome. has been described that is associated with cough and GOR [3]. Linkage to chromosome 3p22-p24 has been found in families with this novel variant of HSN1.

The cough reflex plays a vital role in protecting the airways from inhaled irritants and pathogens. Mechanical and chemical stimuli may initiate the cough reflex by activating irritant receptors, such as transient receptor potential vanilloid type-1 and transient receptor potential ankyrin type-1 receptors [8]. These receptors are widely distributed in the upper and lower airways, oesophagus and external auditory canals. These signals are transmitted via the vagus to the cough centre in the medulla and nucleus tractus solitarius.

Aspiration of gastric contents into the lungs (airways reflux) and a vagally mediated reflex arc, originating from the distal oesophagus, have been proposed as pathophysiological mechanisms in GOR-related cough and airway reflux cough.

The lower oesophageal sphincter (LOS) is a specialised thickened region of circular muscle of the distal oesophagus. Sensory information from the LOS to the brain is conveyed by both spinal and vagal afferents centrally, which have been shown to cause inhibition of transient LOS relaxation. Thus, a vagovagal mediated reflex and can account for a majority of reflux episodes [9]. Since LOS is predominantly controlled by the vagus, an abnormality in the autonomic nervous system was hypothesised to cause airway reflux cough in our patients [10]. Cases 2, 3 and 4 have demonstrable abnormal heart rate variability consistent with this hypothesis. 
In conclusion, we report patients with diverse neurological conditions presenting as airway reflux cough. This highlights the importance of a detailed history and examination in patients with apparently idiopathic cough.

\section{Pradeep S. Karur*, , Jaymin B. Morjaria ${ }^{*, \#}$, Caroline Wright* and Alyn H. Morice* \\ *Division of Cardiovascular and Respiratory Studies, Hull York Medical School, University of Hull, Castle Hill Hospital, Cottingham, UK. "Both authors contributed equally.}

Correspondence: P.S. Karur, Division of Cardiovascular and Respiratory Studies, Hull York Medical School, University of Hull, Castle Hill Hospital, Castle Street, Cottingham, HU16 5JQ, UK. E-mail: karurp@yahoo.co.uk

Statement of Interest: J.B. Morjaria has received honoraria for speaking and financial support to attend meetings from Chiesi, Pfizer, MSD, Boehringer Ingelheim and GSK. A.H. Morice has received honoraria for speaker meetings and financial support to attend meetings/advisory boards from Chiesi, Pfizer, MSD, Boehringer Ingelheim, Novartis, GSK, AstraZeneca, Proctor \& Gamble Healthcare, Orion Respiratory UK, Vectura Ltd, and Nycomed.

\section{REFERENCES}

1 Ford PA, Barnes PJ, Usmani OS. Chronic cough and Holmes-Adie syndrome. Lancet 2007; 369: 342.

2 Kimber J, Mitchell D, Mathias CJ. Chronic cough in the HolmesAdie syndrome: association in five cases with autonomic dysfunction. J Neurol Neurosurg Psychiatry 1998; 65: 583-586.

3 Spring PJ, Kok C, Nicholson GA, et al. Autosomal dominant hereditary sensory neuropathy with chronic cough and gastrooesophageal reflux: clinical features in two families linked to chromosome 3p22-p24. Brain 2005; 128: 2797-2810.

4 Jardine DL, Melton IC, Bennett SI, et al. Baroreceptor denervation presenting as part of a vagal mononeuropathy. Clin Auton Res 2000; 10: 69-75.

5 Morice AH, Faruqi S, Wright CE, et al. Cough hypersensitivity syndrome: a distinct clinical entity. Lung 2011; 189: 73-79.

6 Kinekawa F, Kubo F, Matsuda K, et al. [Gastroesophageal reflux disease in diabetic patients]. Nihon Rinsho 2004; 62: 1546-1552.

7 Kinekawa F, Kubo F, Matsuda K, et al. Relationship between esophageal dysfunction and neuropathy in diabetic patients. Am J Gastroenterol 2001; 96: 2026-2032.

8 Morice AH, Geppetti P. Cough. 5: The type 1 vanilloid receptor: a sensory receptor for cough. Thorax 2004; 59: 257-258.

9 Boeckxstaens GE. The lower oesophageal sphincter. Neurogastroenterol Motil 2005; 17: Suppl. 1, 13-21.

10 Dobrek L, Nowakowski M, Sygula A, et al. 24-hour heart rate variability in patients with gastroesophageal reflux disease. Folia Med Cracov 2005; 46: 53-64.

\section{Treat-to-target approach in pulmonary arterial hypertension: a consensus-based proposal}

\section{To the Editor:}

Goal-oriented therapy, also known as treat-to-target therapy, is recommended in the European Society of Cardiology (ESC)/ European Respiratory Society (ERS) guidelines for the diagnosis and treatment of pulmonary hypertension [1,2]. This approach, first described by HOEPER et al. [3], has emerged, alongside early detection, as a central aspect of managing pulmonary arterial hypertension (PAH). Goal-oriented therapy is proactive as it defines treatment goals ahead of time and proposes to alter the treatment strategy if those goals are not met.

In a review article on goal-oriented therapy in PAH by SITBON and GALIE [4], the authors noted that existing treatment goals are mainly based on parameters with prognostic value at baseline and highlighted the need for additional data to identify goals that have prognostic relevance during treatment. Subsequently, a single-centre study in 109 patients with idiopathic PAH has provided evidence to support the prognostic importance of achieving certain goals during therapy [5]. In this study, the following parameters were individually associated with improved prognosis when assessed at the first follow-up visit (3-12 months after initiation of PAH-specific therapy), supporting their use as treatment goals: 1) improvement to, or maintenance of, New York Heart Association/World Health Organization functional class (FC) I or II; 2) cardiac index $\geqslant 2.5 \mathrm{~L} \cdot \mathrm{min}^{-1} \cdot \mathrm{m}^{-2}$; 3) mixed venous oxygen saturation $\geqslant 65 \%$; or 4) N-terminal pro-brain natriuretic peptide (BNP) levels $<1,800 \mathrm{ng} \cdot \mathrm{L}^{-1}[5]$.

The review by SItBON and GALIE [4] also highlighted that combining baseline parameters may improve prediction of survival in PAH, and emphasised the need for multiple treatment goals. In a recent multicentre study of 226 consecutive patients with idiopathic or familial PAH, the combined use of baseline values for peak oxygen uptake and pulmonary vascular resistance (PVR) provided a more comprehensive prognostic assessment than either parameter alone [6]. Taking the concept a step further, two independent risk scores that combine multiple clinical parameters to predict prognosis have been developed $[7,8]$. In a recent single centre, retrospective study that independently validated the REVEAL (Registry to Evaluate Early and Long-Term PAH Disease Management) score [8], it was shown that assessment of the REVEAL prediction score in addition to FC enhanced prediction of 